\title{
Aplicación de los semigrupos a las pinturas de colores bajo el enfoque sistémico
}

\section{Semigroups application of the paint colors under the systemic approach}

\author{
Alejandro Martínez Gascón \\ Universidad de Valencia (Retirado) \\ amargas@alumni.uv.es
}

\begin{abstract}
Resumen-Este texto pretende introducir un nuevo modelo para describir, explicar y predecir la interacción de las pinturas de colores entre ellas mismas bajo el enfoque sistémico. Para ello se recurre a una estructura algebraica sencilla, los semigrupos. Además, muestra el enfoque mecanicista actual de la colorimetría o ciencia del color. El modelo propuesto está abierto a la diversidad de materiales que existen para realizar pinturas.
\end{abstract}

Palabras clave-color, pintura, semigrupo, sistemas

Abstract-This paper aims to introduce a new model to describe, explain and predict the interaction of color paintings among themselves under the systemic approach. For this purpose, a simple algebraic structure, semigroups, is used. In addition, this paper shows the current mechanistic approach to colorimetry or color science. The proposed model is open to the diversity of materials that exist to make paintings.

Keywords-color, paint, semigroups, systems

\section{Introdución}

La vista es el principal sentido de los cinco que poseemos las personas con capacidad de visión. Ello viene respaldado cuando delante de percepciones contradictorias elegimos a la visión como verdadera y descartamos los otros sentidos. Esta se caracteriza por transformar la percepción de la luz en imágenes visuales, las cuales están llenas de colores. Lo que explica que gran cantidad de la información que generamos en nuestros dispositivos tenga el fin de generar esas imágenes en nuestra mente. Así que, las pantallas de los dispositivos emiten radiaciones que estimulan la vista para acabar generando una o varias imágenes visuales.
No obstante, también podemos pintar cuadros, por ejemplo, para generar imágenes visuales. Para este texto, nos centraremos en las imágenes que se consiguen mediante pinturas de colores de un mismo tipo de materias la cual entraría dentro del segundo grupo mencionado. La ciencia no acepta que los colores existan o bien solo están en nuestra mente. Así que cuando se hablemos de pinturas de colores debemos entender que son materiales diferentes que provocan colores distintos en nuestra visión.

Primero, en el segundo apartado, veremos una descripción concreta y detallada del problema. Continuaremos con un breve y escueto recorrido histórico del mundo del color. Seguiremos en la descripción de un marco teórico, en donde se manifiesta el enfoque mecanicista actual de la ciencia del color. En quinto lugar, 
mostraremos como partiendo de los principios empíricos podemos transportar un problema científico a un problema matemático, es decir, mientras un científico acepta los axiomas matemáticos para hacer sus cálculos y resolver su problema empírico, como matemáticos aceptaremos los principios como axiomas para resolver lo que se convierte en un problema formal. En el siguiente apartado, tendremos la opción de leer el modelo propuesto el cual queda abierto a varias calibraciones para los distintos tipos de materiales para la pintura. Finalmente, cerraremos con unas conclusiones y daremos paso a las referencias que son el punto final del artículo.

\section{Descripción del problema}

Un pintor artístico que realiza sus propias mezclas con las pinturas para obtener el color deseado solo dispone de dos variables: el color de las pinturas disponibles y la cantidad necesaria de cada pintura. Así que, el pintor debe mezclar las pinturas que tiene con cierta cantidad para llegar a una pintura del color deseado. Lo mismo sucede con las máquinas de "hacer color" que encontramos en las tiendas especializadas y algunos lugares específicos como por ejemplo talleres de chapa y pintura. Estas máquinas disponen de un conjunto de pinturas de colores distintos y eligen la cantidad de cada una de ellas para lograr un nuevo color. Me centraré en esta técnica de "hacer color" y no de hacer pintura porque están en la misma situación que los pintores artísticos. Sin embargo, no ocurre lo mismo con las impresoras de uso doméstico, ya que la pintura es opaca y la tinta de impresora no lo es del todo.

Un detalle que se debe añadir es la unidad mínima de trabajo. Tanto el pintor como la máquina no pueden dividir la unidad tantas veces como quieran. Ello implica definir el concepto de unidad mínima de trabajo, es decir, la cantidad más pequeña que su tecnología les permite trabajar. Obviamente, en ambos casos, no se pueden permitir una aritmética infinita. Este hecho debe quedar reflejado en el modelo de algún modo. Hasta aquí el problema.

En la actualidad, las máquinas consiguen el color deseado con bastante precisión dentro de un mismo entorno o dentro de un mismo tipo de pintura o material. No obstante, cuando se quiere pasar de la pantalla a la impresión en papel, a la pintura de la pared o a cualquier otro entorno, se requiere iniciar un proceso de ensayoerror hasta conseguir el mismo color en todos los entornos. Por lo que creemos que el problema está pendiente de mejores $\mathrm{u}$ otras soluciones.

En este contexto, surge esta pregunta ¿pueden las matemáticas aportar su ayuda? Es decir, ¿existe un modelo matemático que contribuya a disolver esa dificultad? Decimos disolver y no resolver porque nos conformaremos en conseguir reducir el problema, aunque quede bastante por hacer. En este artículo proponemos un modelo matemático candidato a minimizar dicha dificultad. Su principal ventaja reside en la capacidad de adaptación a los distintos tipos de materiales. Conclusión que surge del análisis del modelo.

El objetivo principal del presente artículo es dar a conocer este nuevo modelo a expertos de diversas disciplinas para contribuir a una gama más amplia de modelos. Consecuentemente, creemos que introducir la sistémica en las disciplinas de la física, de la química, de la biología, etc. nos permitirá una mejor coordinación entre ellas. Esto se ve con el hecho de que conocer las relaciones entre las distintas disciplinas además de tenerlas enunciadas $\mathrm{y}$ bien identificadas nos permite movernos con mejor soltura entre ellas. Y sobre todo evita el aislamiento disciplinar, es decir, que una ciencia empiece a profundizar en su campo dejando de un lado las relaciones interdisciplinarias. Por ejemplo, nos preguntamos si hay una relación entre la física y la química ¿a qué ciencia le corresponde estudiarla? En este artículo estudio las pinturas, desde una perspectiva más propia de la física que de la química. Esto se verá más adelante.

Al finalizar el artículo dispondremos de un modelo capaz de poder responder a las preguntas siguientes: ¿cómo mezclar las distintas pinturas para obtener las otras? ¿Cuántas pinturas primarias existen? ¿Cuáles de ellas son primarias? ¿Cómo identificar a las demás pinturas de colores respecto a las primarias? ¿Se puede? ¿Existen equivalencias en la mezcla de pinturas? Queremos remarcar que hablamos de pinturas de colores y no de los colores en sí.

\section{Marco teórico}

En la actualidad se acepta la naturaleza dual de la luz como un ente corpuscular (fotón) y electromagnético (ondular). En la ciencia del color generalmente se recurre al carácter ondular. Para el resto de este texto será indiferente tanto una posición como la otra.

En 1931 CIE desarrolló el modelo más utilizado en la actualidad por la informática y los dispositivos. Este modelo, CIE RGB 1931, el cual ha evolucionado, se basa en la teoría tricromática de la luz. De modo que, al ver una luz, la podemos clasificar según su color en dicho espacio. Dadas las limitaciones del ojo humano estos colores se encuentran dentro de la envoltura convexa [1] que definen los colores primarios en la base canónica, en otras palabras, el espacio RGB se reduce a un cubo con los vértices $(0,0,0),(1,1,1)$ y de lado uno.

Abajo se dispone de dos gráficos que representan a dicho cubo realizado con la tecnología actual. El gráfico de la izquierda representa a los colores que están en los vértices del cubo y cuáles son sus coordenadas. Si hacemos un degradado cromático entre los colores de los vértices surge el gráfico de la derecha. La explicación expuesta es sólo a nivel explicativo. Entrar en cómo se llega a las coordenadas de cada color significa abrir una caja negra que queda mejor explicada en [1] y [2].

La luz interactúa con la materia de manera que puede cambiar su color. Este hecho implica ver a los objetos materiales de distinto color al de la luz incidente. Según [3] entre todas las distintas formas de interactuar cabe destacar dos por su influencia con el color de la luz: la absorción y la difusión. «La absorción es el proceso por el cual la energía radiante se utiliza para promocionar las moléculas en el objeto a estados de energía superior» [3]. «La difusión es la interacción por la cual la luz es redirigida como consecuencia de refracciones y reflexiones múltiples.» [3]. 

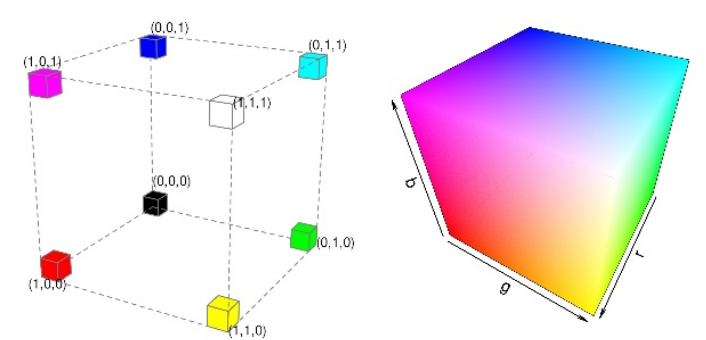

Fig. 1. Exposición gráfica del cubo RGB. A la izquierda se destacan los vértices. A la derecha el cubo con perspectiva.

Aquí termina este escueto marco teórico. Para la finalidad que buscamos no necesitaremos ampliar más porque estudiaremos las relaciones y no sus cajas negras.

\section{Breve recorrido histórico}

Los primeros modelos del color que surgieron a lo largo de la historia son los sistemas de ordenamiento del color. Este tipo de modelo «intenta por lo general incluir todos los colores, al menos en forma teórica, en un modelo topológico, previniendo una posición específica para cada uno de ellos y proponiendo alguna lógica que determine la organización total.» [4]. Diversos autores [4], [1] coinciden en que el primer sistema fue propuesto por Aristóteles (i384 - 322 a.C.). No obstante, los más influyentes en el conocimiento actual son: el círculo de Isaac Newton (1704), la rueda de Johann Wolfgang von Goethe (1808-1810), el triángulo de James Clerk Maxwell (1860). Pero es en el siglo XX cuando se produce una explosión de estos modelos. Entre ellos, cabe destacar el sistema de Munsell (1905, 1921).

Siguiendo en el s. XX, vemos que en este periodo se produce el nacimiento de los espacios de color basados en los espacios vectoriales y en la geometría del espacio tridimensional debido a las leyes formuladas por Hermann Günter Grassmann (1853) y también a la percepción tricromática descrita inicialmente por Thomas Young (1802) y reforzada por Hermann Ludwig von Helmholtz (1891). Mientras que los sistemas de ordenamiento del color son escalas unidimensionales, diagramas bidimensionales, sólidos (tridimensionales), etc. los espacios de color pretenden ser todo un espacio tridimensional, generalmente euclidiano, en el que se acepta, de manera implícita, que solo un subconjunto de todos los colores posibles es perceptible por el sistema visual humano. La Commissión Internationale de l'Eclairage (CIE) desarrolló los más importantes en la actualidad entre los cuales cabe destacar CIE RGB 1931 y CIE XYZ 1931. Estos espacios sufrirán pequeñas correcciones que dan lugar a muchas versiones.

Dado que hay una grandísima variedad de modelos, los podemos clasificar en dos grupos. Los que se basan en la apariencia del color, que son aquellos que solo usan criterios fundados en la percepción subjetiva del color, y los que no se basan en la apariencia del color. Estos últimos se apoyan generalmente en alguna magnitud física de la luz o alguna magnitud química de la materia.

\subsection{El enfoque mecanicista del marco actual}

A continuación, veremos una característica del enfoque actual en la ciencia del color sobre sus objetos de estudio. Para llegar a esa conclusión estableceremos dos caminos distintos. Ambos caminos nos serán útiles para construir un puente entre el enfoque jerárquicomecanicista de pensamiento lineal y el enfoque sistémico.

Por un lado, la luz que incide en la retina del ojo humano generalmente y de forma esquemática proviene de la reflexión en un objeto material que ha producido un foco de luz sobre él. Así pues, se establece una jerarquía lineal en las interacciones entre luz, materia y sistema visual (foco - luz - materia - luz - ojo) dando el mayor rango categórico a la luz. Por ello, y sin que deje de ser una impresión subjetiva, esta es una posible causa que ha producido que el estudio del color resida en el estudio de la luz basada en un pensamiento de orden lineal.

Por otro lado, también tenemos que la colorimetría es una parte de la óptica y no de la química. La posible causa de ello, la encontramos en la historia. De hecho, cuando I. Newton estudió las propiedades ópticas de la luz también estudió los colores. Dada la influencia que ejerce el matemático y físico británico en el surgimiento del método científico es comprensible que se mantenga dentro de la óptica. Como se ve, otra vez hemos de recurrir a la jerarquía histórica que el humano establece para explicar el presente científico. Todo ello significa que el paradigma sistémico aún no ha llegado a la colorimetría o a la ciencia del color.

El análisis sistémico, en cambio, consiste en dividir la realidad en partes o subsistemas sin olvidar sus relaciones. Una primera división del mundo del color es la siguiente: luz, materia y ser humano (o de forma más amplia ser vivo con visión). Al profundizar en la ciencia del color vemos que el análisis anterior, aun sin las relaciones entre ellas, concuerda con la división actual en la que se organiza la ciencia. Así encontramos que la luz es estudiada por la radiometría, la fotometría y la colorimetría, ciencias pertenecientes a la física; la materia es estudiada por la química la cual estudia los colorantes; y el ser humano es estudiado por una gran diversidad de ciencias como son: biología, medicina y psicología; entre ellas también está la optometría. Si esto se lleva desde un enfoque mecanicista, tendremos a muchas ciencias estudiando el color en su ámbito de forma desconectada de las demás con los riesgos que ello conlleva para el conocimiento y el buen funcionamiento de la ciencia. Por ello, decimos que la ciencia del color debe tener entre sus referencias diversas aportaciones de la teoría de sistemas. Algo que hecho en falta.

A pesar del vasto mundo del color, este artículo pretende estudiar sólo una minúscula parte de este sistema que a tantas ciencias implica porque de lo contrario no cabría en estas páginas. Esa minúscula parte ya es un sistema como veremos a continuación. En ese sistema destacamos la interacción de la luz con la pintura. La luz es un flujo que al interactuar con la pintura sufre unos cambios. Así que, nos interesa estudiar no el porqué del cambio, tampoco qué hace que cambie sino simplemente describir el cambio que sufre dada la pintura en cuestión. Seguidamente, expongo un gráfico elemental de dicha interacción basado en los gráficos de caja negra. 


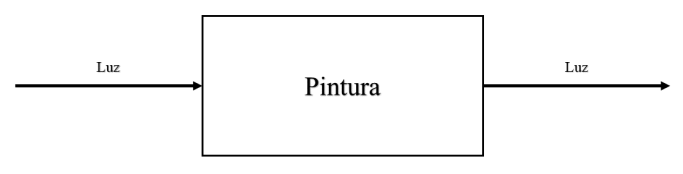

Fig. 2. Esquema gráfico del sistema.

La luz saliente de un foco, si es percibida, tendrá un color. Este color se puede expresar en una variable vectorial de tres dimensiones mediante el cubo RGB, un sistema de CIE. Cuando la luz incida en la pintura, se producirá una interacción que afectará o no a su longitud de onda e intensidad. Ello provoca que si es percibida nuevamente pueda verse de otro color, el cual queda expresado otra vez como un vector tridimensional mediante el cubo RGB. El enfoque sistémico requiere que se digan todas las relaciones entre las partes. Así que debemos relacionar la luz incidente con la reflejada. Este aporte sistémico que pretendemos dar. Un paso que es muy notable porque nos obliga a no ignorar una necesidad imprescindible.

Queremos remarcar que no vamos a abrir ninguna de las cajas negras que la ciencia ha estudiado. Sólo vamos a estudiar las relaciones que hay entre la caja negra luz y la caja negra pintura bajo la perspectiva del ojo humano sin tener en cuenta la información de una máquina sobre la luz, en la medida de lo posible. Así que no importa la composición química de la pintura, tampoco debería importar la naturaleza de la luz (si son fotones u ondas) y ni tampoco las demás cajas negras que las diferentes ciencias estudian por su cuenta para este artículo.

Como comentario hay que decir que las diferentes disciplinas dan la impresión de trabajar bajo la máxima independencia posible. Ello provoca que eviten las interconexiones entre ellas. A su vez, me pregunto, ¿a qué ciencia corresponde estudiar las conexiones entre disciplinas? Sin duda será una ciencia interdisciplinaria y sistémica, a pesar de que no tengamos una respuesta o una ciencia candidata.

\section{Principios del modelo}

En este apartado voy a trasladar los principios de la realidad de las pinturas de colores a axiomas matemáticos. Ello nos permitirá transportar un problema científico a un problema matemático. Estos principios se basan en la observación y los tomamos como ciertos, aunque muchas veces se aporten observaciones para expresar nuestra postura. Sucede algo parecido con los axiomas, los tomamos como ciertos sin ofrecer ninguna demostración, aunque muchas veces ofrecemos argumentos propios para aceptarlos.

El objetivo del modelo es facilitar el trabajo a los pintores en su tarea de mezcla de pinturas para obtener otras de colores distintos. Para ello, vamos a identificar cada pintura en la mezcla de las pinturas primarias independientemente de la luz que incida sobre ella. Lo cual requiere contestar a las preguntas: ¿cuántas pinturas primarias existen? ¿Cuál de las pinturas se puede considerar primaria? Una pintura de color es primaria cuando no se puede obtener una unidad mínima de trabajo como mezcla de otras pinturas. Por lo tanto, debo hacer primero todas las combinaciones y luego responder a las preguntas. Así que quedará respondida cuando se finalice el modelo. Nótese que definir una unidad mínima de trabajo, como decía al principio, nos será útil para realizar todas las combinaciones posibles porque si trabajamos con aritmética infinita tendremos una infinidad de posibilidades.

Lo que pretendemos se verá más claro con un ejemplo. Imaginemos que tenemos 5 pinturas de color diferentes. Por ejemplo, el rojo, amarillo, naranja, blanco y rosa. Para simplificar la explicación supondremos que la luz incidente es blanca. Tomo como unidad mínima de trabajo el mililitro, ml. El volumen de los tintes es $1 \mathrm{ml}$. para rojo, amarillo, blanco, naranja y $2 \mathrm{ml}$. rosa. Así tendremos que las pinturas primarias con este grupo reducido son: rojo, amarillo, blanco y naranja. Este último se incluye como pintura primaria porque no puedo obtener $1 \mathrm{ml}$. de ella a partir de mezclar las anteriores, dado que mi unidad mínima de trabajo es $1 \mathrm{ml}$. Por otro lado, el rosa se puede obtener como mezcla de rojo y blanco dando lugar a $2 \mathrm{ml}$. de rosa. Así que añadir el rosa de $2 \mathrm{ml}$. no aporta nada nuevo; mientras que la pintura naranja nos reducía su unidad de trabajo. Pasemos a ver los principios y axiomas del modelo.

En primer lugar, en la descripción del problema se ponía de manifiesto una de las principales condiciones del modelo: las dos variables de acción han de ser la cantidad de pintura y el color de ella. Esto es lo mismo que decir que existe un conjunto $\mathrm{P}$ (de pinturas) no vacío de manera que cada uno de sus elementos queda determinado unívocamente por una variable cuantitativa y otra cualitativa.

En segundo lugar, la variable cuantitativa debe ser numerable. Esto se debe a que partíamos de una cantidad mínima de trabajo la cual no podemos subdividir y en base a ella debemos realizar todas las demás mezclas. Esto implica que la variable se mueve en los números naturales. El conjunto de los enteros queda descartado porque dada una mezcla de pinturas cualesquiera es imposible, con los medios comunes de un pintor artístico, deshacer la mezcla para obtener sus componentes, es decir, no se puede restar (quitar) una pintura a otra.

Estas condiciones pueden parecer artificiales. No obstante, y en todo caso, nos serán de utilidad para tener un modelo más sencillo. Más adelante, se podrá crecer en la complejidad y obtener un modelo más natural. Seguidamente, enunciamos el primer axioma:

\section{Primer axioma}

Sea $\mathrm{P}=\mathrm{N} \times \mathrm{C}$, donde $\mathrm{N}=$ naturales, $\mathrm{C} \neq \varnothing$ representa la variable cualitativa de los colores. Por tanto, $\mathrm{p}_{1}=\left(\mathrm{n}_{1}\right.$; $\mathrm{c}_{1}$ ). Separo con un punto y coma para dejar claro que $\mathrm{n}_{1}$ es un tipo de variable $\mathrm{y}_{1}$ es otro tipo de variable - tal vez se necesiten más de un número para $\mathrm{c}_{1}$.

En tercer lugar, observamos frecuentemente que las pinturas, al mezclarlas y remover lo suficiente, producen un cambio en el color y un cambio en la cantidad. Ello nos lleva a afirmar que existe una ley de composición interna 
entre las pinturas de colores, es decir, dos pinturas cualesquiera dan lugar a otra pintura perteneciente al conjunto P. Dada que la primera variable es cuantitativa, $\mathrm{N}$, conocemos que ley de composición interna es la de los naturales, pero la suma entre los colores, la variable cualitativa, deberemos descubrirla. Seguidamente, enunciamos el segundo axioma:

\section{Segundo axioma}

Sabemos que existe una L.C.I., es decir, una ley de composición interna (nótese que en álgebra definir una suma no implica siempre definir una resta. La suma y la resta pueden existir como leyes de composición interna sin que una implique la otra). Así que, para todo par de pinturas, $\left(\mathrm{p}_{1}, \mathrm{p}_{2}\right)$, se obtiene otra pintura de color. $\mathrm{p}_{1}+\mathrm{p}_{2}$ $=\left(\mathrm{n}_{1} ; \mathrm{c}_{1}\right)+\left(\mathrm{n}_{2} ; \mathrm{c}_{2}\right)=\left(\mathrm{n}_{1}+\mathrm{n}_{2} ; \mathrm{c}_{1}+\mathrm{c}_{2}\right)$. Mientras que la suma cuantitativa la conocemos porque es la propia de los naturales, la suma de la variable cualitativa, +', la desconocemos y debemos descubrirla a través de los datos y el siguiente axioma.

En cuarto lugar, sabemos que una pintura mezclada entre ella misma no altera su color, esto es, $\mathrm{p}+\mathrm{p}=$ [axioma $1]=(\mathrm{n} ; \mathrm{c})+(\mathrm{n} ; \mathrm{c})=[$ axioma 2$]=\left(\mathrm{n}+\mathrm{n} ; \mathrm{c}+{ }^{\prime} \mathrm{c}\right)=$ [propiedad de los naturales y ley empírica] $=(2 n ; c)$. Esta es una condición fuerte a nivel algebraico y debe quedar reflejado en los axiomas.

\section{Tercer axioma}

Para todo color, $\mathrm{c}$ de $\mathrm{C}, \mathrm{c}+{ }^{\prime} \mathrm{c}=\mathrm{c}$.

En quinto lugar, se observa fácilmente que las pinturas cumplen la asociativa y la conmutativa debido al mezclado homogéneo. Lo que nos lleva a afirmar que la variable cualitativa pertenece a un conjunto con una ley de composición interna conmutativa y asociativa. Veamos el razonamiento empírico.

$\mathrm{p}_{1}+\mathrm{p}_{2}=\mathrm{p}_{2}+\mathrm{p}_{1}$ por observación, entonces $\left(\mathrm{n}_{1} ; \mathrm{c}_{1}\right)+$ $\left(\mathrm{n}_{2} ; \mathrm{c}_{2}\right)=\left(\mathrm{n}_{2} ; \mathrm{c}_{2}\right)+\left(\mathrm{n}_{1} ; \mathrm{c}_{1}\right)$ lo que implica que $\mathrm{n}_{1}+\mathrm{n}_{2}=\mathrm{n}_{2}$ $+\mathrm{n}_{1}$-que ya sabíamos- y $\mathrm{c}_{1}+{ }^{\prime} \mathrm{c}_{2}=\mathrm{c}_{2}+{ }^{\prime} \mathrm{c}_{1}$-que desconocíamos.

$\mathrm{p}_{1}+\left(\mathrm{p}_{2}+\mathrm{p}_{3}\right)=\left(\mathrm{p}_{1}+\mathrm{p}_{2}\right)+\mathrm{p}_{3}$, análogamente, se llega a que $c_{1}+{ }^{\prime}\left(c_{2}+c_{3}\right)=\left(c_{1}+{ }^{\prime} c_{2}\right)+{ }^{\prime} c_{3}$. Seguidamente, enunciamos el siguiente axioma.

\section{Cuarto axioma}

$\left(\mathrm{C},+^{\prime}\right)$ es un semigrupo abeliano. En el que se puede incluir como elemento neutro al transparente según convenga.

En sexto lugar, se conoce la existencia de un conjunto reducido de pinturas que generan todas las demás mediante mezclas. Esto no es más que el siguiente axioma:

\section{Quinto axioma}

Existen $\mathrm{p}_{1}, \mathrm{p}_{2}, \ldots, \mathrm{p}_{\mathrm{n}}$ tales que, $\mathrm{p}^{\prime}=\mathrm{p}_{1}+\ldots+\mathrm{p}_{1}+\mathrm{p}_{2}+$ $\ldots \mathrm{p}_{2}+\mathrm{p}_{\mathrm{n}}+\ldots+\mathrm{p}_{\mathrm{n}}$ para cualquier $\mathrm{p}$ ' pintura de color donde $\mathrm{p} 1$ se repite $m_{1}$ veces, $p_{2}$ se repite $m_{2}$ veces, así sucesivamente hasta llegar $\mathrm{p}_{\mathrm{n}}$ se repite $\mathrm{m}_{\mathrm{n}}$ veces.

En séptimo lugar, sabemos que la materia al interactuar con la luz devuelve un color distinto al color de la luz inicial. Dicho de manera más formal, la materia define una aplicación entre los colores de la luz en los colores de la luz. El espacio de color que percibimos de la luz viene generalmente identificado con el espacio RGB.
No obstante, hay una gran diversidad de estos espacios por lo que, de forma opcional, se puede incluir el siguiente axioma si bien se puede adaptar a cualquier otro espacio cromático.

\section{Sexto axioma}

Para cualquier valor de la variable cualitativa, tenemos que esta es una aplicación del espacio cromático RGB al espacio RGB u otro espacio de color, análogamente.

\section{Obtención del modelo}

El apartado anterior contiene todo lo necesario para identificar el ente matemático que encaja en los axiomas anteriores. No obstante, este ente está abierto a una calibración de las pinturas. Mediante la recogida de datos en el laboratorio se conseguiría fácilmente este paso. Se podría decir que el trabajo del matemático acaba en este apartado, pero pueden surgir problemas en lo que otra vez habría que reiniciar el proceso dado la nueva realimentación o feedback.

Se puede demostrar fácilmente que el producto cartesiano de semigrupos abelianos es otro semigrupo abeliano. Por tanto, dado que se ha visto que $\mathrm{C}$ es un semigrupo abeliano y que $\mathrm{N}$ también lo es, $\mathrm{N} \times \mathrm{C}$ es un semigrupo abeliano. Además, por el axioma quinto, este conjunto es finitamente generado. Ello nos lleva a afirmar que hay un cociente en $\mathrm{N}^{\mathrm{k}}$ isomorfo a $\mathrm{N} \times \mathrm{C}$. Lo que significa que con los números naturales vamos a tener suficiente, solo hay que tomar varias dimensiones.

Para completar este punto, comentaremos que el trabajo necesita una calibración del modelo que determine el valor de $\mathrm{k}$ y el cociente $\mathrm{N} / \sim$. Esta calibración se debe realizar a través del mezclado de las pinturas de colores.

Una vez visto el modelo, se ve claramente que esta vez se ha elegido primero el modelo teórico y queda aún por descubrir las variables. Ello significa que se está en pleno feedback ya que [5] establece el siguiente orden en los pasos:

1. «Descripción del problema

2. Construcción de un modelo conceptual

2.1. Elección de los objetos, elementos o variables que tengan alguna relación con los objetivos.

2.2. Identificación de las relaciones causa-efecto entre los elementos.

2.3. Asignación de una representación funcional a las relaciones detectadas (dependencia entre variables, ecuaciones...)

3. Programación del modelo para una computadora o instrucción de un grupo de expertos.

4. Calibrado del modelo

5. Análisis de la sensibilidad

6. Evaluación de la validez o utilidad del modelo para el logro de los objetivos propuestos.

7. Diseño de experimentos o procedimientos de optimización para ser realizados sobre el modelo.

8. Realización de los experimentos o de procedimientos de optimización diseñados.

9. Presentación de los resultados obtenidos. 
10. Toma de decisiones.»

Evidentemente el paso 2.3. se ha substituido por elección del modelo algebraico sin que sea un cambio rompedor de la metodología. También podemos ver que la previsión del quinto paso, en donde se nos pide el análisis de la sensibilidad, consta en el concepto de unidad mínima de trabajo.

\section{Conclusiones}

El modelo que se ha presentado es flexible a la diversidad de materiales o de pinturas de colores de distinto tipo, es decir, dependiendo del material que se use se pueden tener pequeñas variaciones en la calibración. Esta es una ventaja frente a los demás modelos que presumen describir el comportamiento de los colores como si no dependiese de nada más que del color en sí. Las observaciones que [6] destaca en los filtros translúcidos de luz dan pie a pensar que en distintas pinturas ocurran estructuras o comportamientos distintos.

El camino recorrido para obtener los resultados expuestos es casi inverso al camino tradicional. Con este modelo primero describiremos las pinturas de colores y de ahí extraeremos el comportamiento algebraico de los colores. Esto ha sido posible a las realimentaciones propuestas en la metodología de Antonio Caselles antes descrita.

Para finalizar, queremos remarcar el hecho de que vamos a obtener como estructura algebraica un semigrupo abeliano y no un espacio vectorial euclidiano. Ello implica tener un modelo que se ajusta más a la realidad porque contempla la imposibilidad de restar o quitar la pintura ya mezclada.

\section{REFERENCIAS}

[1] J. M. Artigas Verde, P. Capilla Perea, J. Pujol i Ramo y U. d. València, Fundamentos de colorimetría, Valencia: Publicacions de la Universitat de València, 2002.

[2] R. D. Lozano y B. H. Crawford, El color y su medición: con una introducción a la óptica fisiológica y al estudio de la visión, Editorial AméricaLee, 1978.

[3] R. M. Christie, La química del color, Zaragoza (España): Acribia, 2003.

[4] J. L. Caivano, «Sistemas de orden del color,» Serie Difusión (0328-2252), 1995.

[5] A. Caselles Moncho, Modelización y simulación de sistemas complejos, Publicacions de la Universitat de València, 2008.

[6] J. Barrio, «La complejidad de las mezclas sustractivas y su predicción a partir del análisis espectral.,» Revista Eureka sobre Enseñanza y Divulgación de las Ciencias, pp. 427-436, 2011.

[7] M. J. Beltrán-Meneu y M. Murillo-Arcila, «Coloreando el Álgebra Lineal,» Modelling in Science Education and Learning, pp. 25-33, 2016.

[8] P. A. García Sánchez, Semigrupos afines, Granada: Universidad de Granada, 2013.
[9] P. D. Romero Sánchez, Modelos de deconvolución ciega fraccionaria. Aplicaciones a la restauración de obras pictóricas., Valencia, 2009. 